\section{Endoscopic retrieval of a toothbrush in the esophagus}

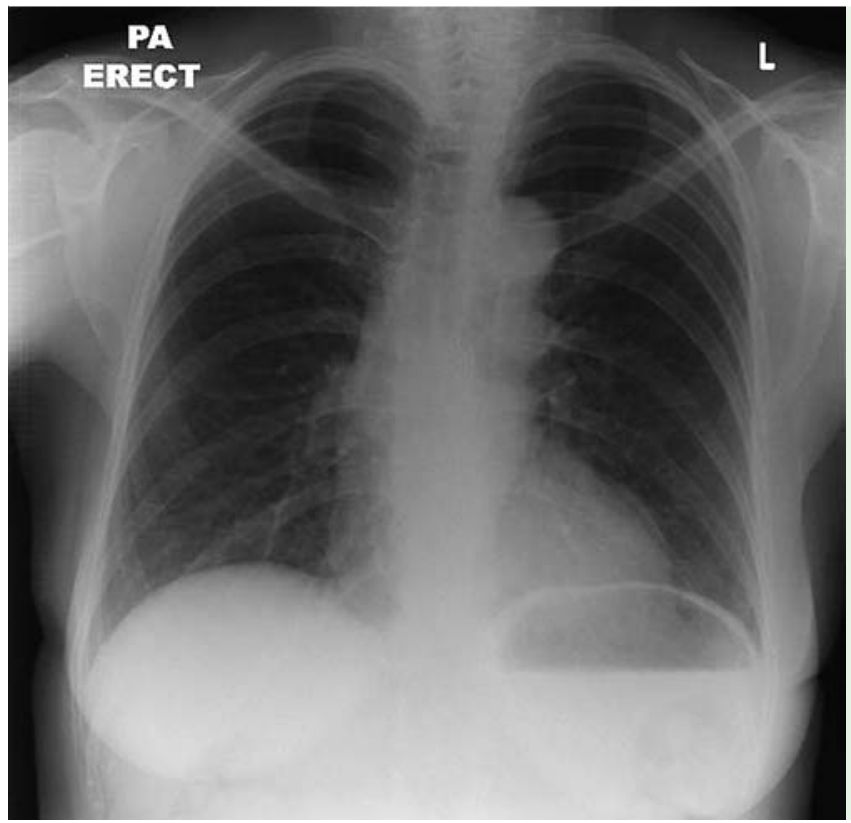

Fig. 1 Chest radiograph showing the head of the toothbrush in the mid-esophagus.

A 55-year-old woman presented to the hospital following the unintentional swallowing of a toothbrush. The patient had been feeling nauseous and had tried to self-induce vomiting by inserting the toothbrush, having failed with her fingers. The patient had introduced the toothbrush into the oropharynx, which initiated a swallow during which the patient lost her grip of the toothbrush handle. The patient developed subsequent chest discomfort. She was still able to swallow fluids and saliva. There were no underlying medical or psychiatric problems.

A chest radiograph showed the toothbrush with the bristles below the carina ( Fig.1). Esophagogastroduodenoscopy (EGD) was performed, and the handle of the toothbrush was seen in the laryngo- pharynx ( Fig.2). The use of a polypectomy snare allowed gradual removal of the toothbrush until it was visible with a laryngoscope. Magill forceps were used to remove the toothbrush. The patient had an uneventful recovery.

Foreign body ingestion is common in the pediatric population and is generally accidental. In the adult population, however, foreign body ingestion tends to be intentional, occurring in the setting of psychiatric disease, developmental delay, alcohol intoxication, and individuals with secondary gain (i.e. prisoners, drug smugglers). Most ingested foreign bodies do not require intervention and pass naturally. However, the rate of intervention is higher in situations where items have been ingested intentionally.
The American Society for Gastrointestinal Endoscopy (ASGE) produced guidelines in 2011 to aid decision making [1]. The need for and timing of endoscopy depend upon several factors: patient age, clinical condition, and factors relating to the foreign body (size, shape, content, location of object). EGD with conscious sedation has a high success rate. An overtube should be used to protect both the airway and the esophageal mucosa from small objects and injury. Various devices have been used to retrieve the foreign body including forceps, polypectomy snares, polyp graspers, and nets.

Endoscopy_UCTN_Code_TTT_1AO_2AL

Competing interests: None

Benjamin R. Disney, Sharanabasappa Shetty

Department of Gastroenterology, Russell's Hall Hospital, Dudley, United Kingdom

\section{Reference}

1 ASGE Standards of Practice Committee. Management of ingested foreign bodies and food impactions. Gastrointest Endosc 2011; 73: $1085-1091$

\section{Bibliography}

DOI http://dx.doi.org/ 10.1055/s-0034-1377496

Endoscopy 2014; 46: E449-E450

(c) Georg Thieme Verlag KG

Stuttgart · New York

ISSN 0013-726X

\section{Corresponding author}

\section{Benjamin R. Disney, MD}

Department of Gastroenterology

Russell's Hall Hospital

Dudley

DY1 2HQ

United Kingdom

b.disney@nhs.net

- Figs. 2a, b, c see following page. 


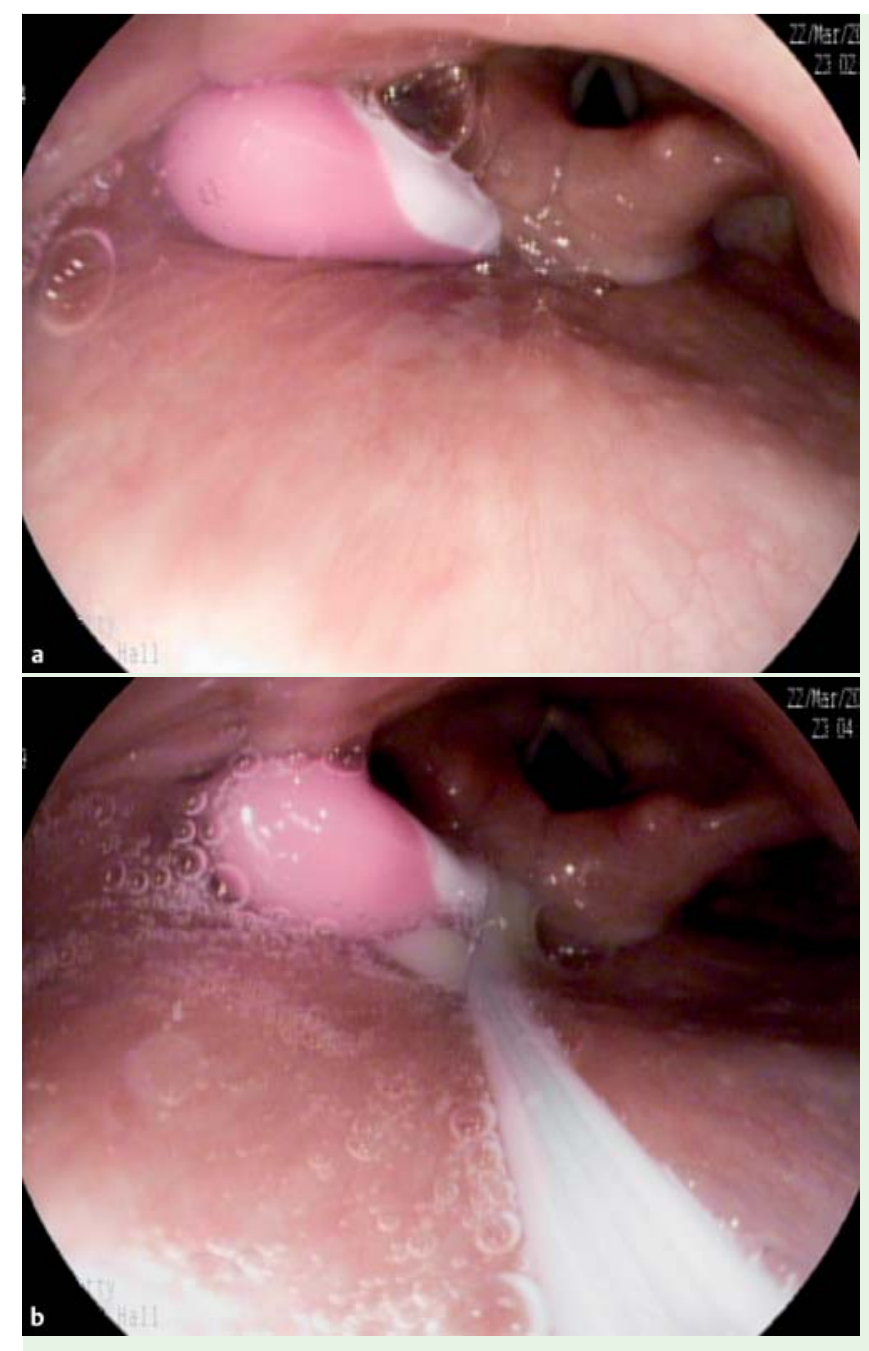

Fig. 2 Endoscopy to retrieve the toothbrush from the oropharynx. a The toothbrush traversing the upper esophageal sphincter.

b A polypectomy snare and Magill forceps were used to grasp and remove the toothbrush. c The toothbrush following successful removal. 